\title{
HUBUNGAN DUKUNGAN KELURGA DAN DUKUNGAN TENAGA KESEHATAN DENGAN KEPATUHAN PASIEN KANKER DALAM MENJALANKAN KEMOTERAPI DI RS ISLAM SITI RAHMAH TAHUN 2018
}

\author{
${ }^{1}$ Zuriati, S.Kep, Ns, M.Kep, ${ }^{2}$ Melti Suriya, S.Kep, Ns, M.Kep, ${ }^{3}$ Risdayeti, S.Kep \\ ${ }^{1}$ Prodi Ners STIKes Alifah, Jln Khatib Sulaiman No 52 Padang 25000. Indonesia \\ Email: zuriati3781@gmail.com \\ ${ }^{2}$ Prodi Ners STIKes Alifah, Jln Khatib Sulaiman No 52 Padang 25000. Indonesia \\ Email: suriyamelti@gmail.com \\ ${ }^{3}$ Prodi Ners STIKes Alifah, Jln Khatib Sulaiman No 52 Padang 25000. Indonesia \\ Email: risdayeti@gmail.com
}

\begin{abstract}
ABSTRAK
Efek samping dari kemoterapi dapat menimbulkan ketidak patuhan pasien untuk menjalankan kemoterapi. Penelitian ini bertujuan untuk mengetahui hubungan dukungan keluarga dan dukungan tenaga kesehatan dengan kepatuhan pasien kanker dalam melaksanakan kemoterapi di RS. Islam Siti Rahmah Padang Tahun 2018. Jenis penelitian ini adalah deskriptif analitik dengan menggunakan desain cross sectional study. Populasi dalam penelitian ini penderita kanker yang menjalani kemoterapi, dengan teknik pengambilan sampel secara accidental samplingvyang berjumlah 30 orang. Penelitian ini menggunakan analisis univariat dan bivariat dengan menggunakan uji chi-square. Hasil penelitian didapatkan 53,3\% responden tidak patuh dalam melaksanakan kemoterapi, 63,3\% dukungan keluarga yang kurang, 53,3\% dukungan petugas kurang. Terdapat hubungan dukungan keluarga ( $\mathrm{p}$ value $=0,011$ ) dan dukungan petugas kesehatan ( $\mathrm{p}$ value $=0,030$ )dengan kepatuhan pasien kanker dalam melaksanakan kemoterapi di RS. Islam Siti Rahmah Padang Tahun 2018. Diharapkan bagi petugas kesehatan atau perawat yang memberikan asuhan keperawatan pada pasien kanker yang menjalani kemoterapi agar dapat memberikan dukungan maksimal dengan cara memberikan penjelasan yang lengkap tentang manfaat, efek samping dan cara kerja kemoterapi baik pada pasien maupun pada keluarga sehingga keluarga juga dapat memberikan dukungan yang maksimal pada pasien kanker yang menjalani kemoterapi tersebut.
\end{abstract}

Kata Kunci

: Dukungan Keluarga, Dukungan Tenaga Kesehatan, Kepatuhan, Kemoterapi

\begin{abstract}
Side effects of chemotherapy can lead to patient non-compliance to run chemotherapy. This study aims to determine the relationship of family support and support of health personnel with the compliance of cancer patients in carring out chemotherapy in RS. Islam Siti Rahmah Padang Year 2018. The type of this research is descriptive analytic by using cross sectional study design. The population in this study of cancer patients who underwent chemotherapy, with sampling technique by accidental sampling of 30 people. This study used univariate and bivariate analysis using chi-square test. The result showed $53.3 \%$ of respondents did not adhere to chemotherapy, $63.3 \%$ lack of family support, 53.3\% lack of support staff. There is a relation of family support ( $p$ value $=0,011$ ) and support of health officer ( $p$ value $=0,030$ ) with patient compliance of cancer in carrying out chemotherapy at RS. Islam Siti Rahmah Padang Year 2018.It is expected that health care workers or nurses who provide nursing care to cancer patients undergoing chemotherapy in order to provide maximum support by providing a complete explanation of the benefits, side effects and how well chemotherapy in both patients and families so that families can also provide maximum support in cancer patients undergoing such chemotherapy.
\end{abstract}

Keywords: Family Support, Health Care Support, Compliance, Chemotherapy 


\section{PENDAHULUAN}

Penyakit kanker merupakan salah satu masalah kesehatanmasyarakat di dunia. Kanker dapat menyerang berbagai jaringan di dalamorgan tubuh. Kanker adalah penyakit ginekologik yang memiliki tingkatkeganasan yang cukup tinggi. Angka kejadian dan angka kematian akibatkanker di dunia menempati urutan pertama.Sementara itu di negara berkembang masih menempati urutan teratassebagai penyebab kematian akibat kanker di usia reproduktif (Rasjidi,2013).

Kanker adalah suatu penyakit yang disebabkan oleh pertumbuhan sel-sel jaringan tubuh yang tidak normal. Sel-sel kanker akan berkembang dengan cepat, tidak terkendali, dan akan terus akan membelah diri selanjutnya menyusup ke jaringan di sekitarnya (invasive) dan terus menyebar melalui jaringan ikat, darah dan menyerang organ-organ penting serta saraf tulang belakang (Kemenkes RI, 2014).

Kanker salah satu penyebab utama morbiditas (kondisi yang mengubah kualitas hidup dan kesehatan). Menurut badan kesehatan dunia WHO pada tahun 2012 diperkirakan terdapat 14 juta kasus kanker, dan sekitar 8,2 juta diantaranya dinyatakan meninggal dunia akibat kanker. Jenis kanker yang banyak menyebabkan kematian di antaranya, kanker paru-paru (1,59 juga kasus), kanker hati (745 ribu kasus), kanker perut (723 ribu kasus), kanker kolon (694 ribu kasus), kanker payudara (521 ribu kasus), kanker esopagus (400 ribu kasus), dan kanker lainnya sampai mencapai angka 8,2 juta kasus kematian akibat kanker.

Untuk prevalensi penyakit kanker di Indonesia secara keseluruhan memiliki persentase 1,6 per seribu penduduk sama dengan 328 ribu orang, dengan perincian menurut propinsi, posisi paling tinggi terdapat di Yogyakarta dengan 4,1\%, lalu di Jawa Tengah dengan 2,1\%, diikuti oleh Bali dengan $2 \%$, dan DKI Jakarta serta Bengkulu masing-masing 1\% (Kemenkes RI, 2016).

Lokasi kanker dan pola penyebaran membuat tindakan operasi bukanpilihan utama pada penanganan kanker.Pilihan utama adalahradioterapi, karena bersifatradiosensitif. Radioterapi bertujuan untuk mematikan sel tumor tanpa merusakstruktur jaringan normal di sekitarnya, tetapi pada pemberian radioterapi dosistinggi dan jangka waktu yang lama kerusakan struktur jaringan normal sulitdihindari. Pada stadium awal, pemberian radioterapi untuk tujuan kuratif,sedangkan pada stadium lanjut diberikan untuk paliatif. Penatalaksanaan atau pengobatan utama penyakit kanker meliputi empatmacam yaitu pembedahan, radioterapi, kemoterapi, dan hormonterapi.Kemoterapi adalah alternatif pengobatan yang dilakukan untuk penderitakanker (Smeltzer \& Bare, 2012).

Kemoterapi dilakukan untuk membunuh selkanker dengan obat anti-kanker (sitostatika), dimana sitostatika merupakangolongan obat-obatan yang dapat menghambat pertumbuhan kanker bahkanada yang dapat membunuh sel kanker. Obat ini termasuk obat-obat berbahayayaitu obatobat yang genotoksik, karsinogenik, dan teratogenik dan ataumenyebabkan kerusakan fertilitas (Sukardja, 2013). Adapun jenisjenis obatsitostatika yang mempunyai sifat toksik bagi tubuh diantaranya 5 FU,Doxorubin, Cisplatin, Methotrexate dan lain-lain (Otto, 2015).

Penelitian yang dilakukan Sirait (2014) di Rumah Sakit Cipto MangunkusumoJakarta (RSCM), frekuensi tertinggi penderita kanker datang berobat padastadium III $(46,5 \%)$ diikuti stadium II (31.9\%), stadium I (14,5\%) dan stadiumIV $(7,1 \%)$. Jadi umumnya penderita ke Rumah Sakit sudah dalam stadiumlanjut, dengan demikian pengobatan kemoterapi pada kanker stadium IIIpaling sering digunakan di Indonesia (Alle, Hardjanta, \& Suharsono, 2013).Pasien kanker yang menjalani pengobatan kemoterapi, biasanya mengalamiefek fisiologis yang tidak menyenangkan seperti rambut rontok, menurunnyakadar sel darah sehingga penderita lebih mudah lelah atau mengalamipendarahan, kulit menjadi hitam, kering serta gatal-gatal, mual, muntah dannyeri perut serta menurunnya nafsu seksual dan tingkat fertilitas (Susanti \&Tarigan,2012). 
Efek samping kemoterapi timbul karena obat-obat kemoterapitidak hanya menghancurkan sel-sel kanker tetapi juga menyerang sel-selsehat terutama yang membelah dengan cepat, efek tersebut menimbulkanperubahan dalam kehidupan pasien yang sedang menjalani kemoterapi. Disamping efek fisiologis pada penderita kanker yangmenjalani kemoterapi juga mengalami efek psikologis yang semakin beragam,antara lain kecemasan, rasa takut akan kematian, takut menjadi beban, takutditinggalkan, ketidakmampuan dan gangguan harga diri (Kova \& Miha, 2011).

Kepatuhan kemoterapi dapat dipengaruhi oleh dukungan keluarga dan dukungan petugas kesehatan. Kemoterapi menyebabkan melosupresi sehingga menimbulkanrisiko infeksi dan perdarahan. Kerusakan membran mukosamenyebabkan gangguan pencernaan. Mual dan muntah merupakanefek samping yang sangat ditakutkan oleh pasien pada waktu akanmenjalani kemoterapi. Semua jaringan yang membelah dengan cepatseperti folikel rambut (alopesia) dan epitel saluran germinal(infertilitas) sangat rentan terhadap efek kemoterapi. Kadangkala proses penanganan kanker sangat membebani pasiendibandingkan penyakitnya sendiri, misalnya proses radiasi dan obat-obatanyang digunakan untuk membunuh sel kanker ternyata dapatmenyebabkan kerusakan tubuh bahkan berpotensi untuk menyebabkanhilangnya fungsi tubuh yang tidak dapat diperbaiki (Lubis \& Hasnida,2012).

Hasil penelitian sebelumnya yang dilakukan oleh Harina (2017) menemukan bahwa $82,5 \%$ pasien patuh dalam menjalani kemoterapi, $56,1 \%$ pemahaman tentang instruksi pasien tinggi dalam menajalani kemoterapi, 52,6\% keluarga memberikan dukungan yang baik kepada pasien, dan 71,9\% efek samping pengobatan yang dialami tidak mengganggu pasien dalam menjalani kemoterapi. Hasil analisis didapatkan adanya hubungan yang signifikan anatara faktor yang berhubungan dengan keapatuhan pasien dalam mejalani kemoterapi adalah pemahaman tentang instruksi, dukungan keluarga, dan efek samping.

Pasien kanker juga mengalami gangguan konsep diri,terutama gambaran diri yaitu suatu sikap individu terhadap tubuhnya,baik secara sadar dan tidak sadar meliputi performance, potensi tubuh,fungsi tubuh, serta persepsi dan perasaan tentang ukuran dan bentuktubuh (Sunaryo, 2014). Keluarga dan teman seringkali sangat dibutuhkansebagai pendamping atau teman dalam menghadapi masa sulit tersebut.Berbicara dengan keluarga dan teman dapat meringankan bebantersebut. Kadang berbagi dengan orang luar lebih mudah dilakukan,misalnya bicara dengan orang yang dituakan atau pemukaagama(Sudoyo, 2012).

Penelitian yang dilakukan oleh Saragih (2010) menunjukkan 20\% dukungankeluarga dan koping pasien dengan penyakit kanker terhadap pengobatankemoterapi tidak baik, sedangkan penelitian Subiatmi (2012) menunjukkanbahwa dukungan keluarga dan perawat sebagian besar baik dan tingkatkecemasan sebagian besar pada ketegori cemas sedang $65 \%$. Berdasarkanpenelitian Fajriati (2013) dukungan sosial, terutama dukungan informasi dandukungan penghargaan sangat diperlukan untuk mencegah terjadinyakecemasan penderita yang ditimbulkan akibat tindakan kemoterapi. Dampakdari kurangnya dukungan sosial yang dialami penderita kanker yang menjalanikemoterapi mempengaruhi kemoterapi yang dijalani seperti tidak mau lagimenjalani kemoterapi karena trauma dengan efek samping kemoterapipenurunan kondisi tubuh yang membuat turunnya hemoglobin sehingga tidakbisa menjalani kemoterapi dan penerimaan obat terhadap tubuh yangmenyebabkan efek samping yang dialami lebih besar dari yang seharusnya (Fajriati, 2013).

Keluarga dapat menjadi faktor yang sangat berpengaruh dalam menentukan keyakinan dan nilai kesehatan individu serta dapat juga menentukan tentang program pengobatan yang dapat mereka terima. Secara umum klien 
yang mendapat perhatian dari seseorang atau kelompok biasanya cenderung lebih mudah mengikuti nasihat medis daripada pasien yang kurang mendapat dukungan sosial. Bagi klien kanker yang mengikuti program kemoterapi dukungan keluarga sangat penting untuk memotivasi mereka agar terus tetap semangat melaksanakan program kemoterapi selanjutnya (Friedman, 2010).

Kepatuhan pasien untuk menjalankan pengobatan yang ditawarkan oleh petugas kesehatan akan sangat dipengaruhi oleh cara petugas kesehatan dalam memberikan informasi tentang pengobatan tersebut. Agar seseorang mau melakukan suatu tindakan tertentu diperlukan dukungan yang efektif antara seorang provider dengan pasien dan/atau keluarganya. Dukungan yang tidak efektif antara petugas kesehatan dengan pasien dan atau keluarganya dapat mengganggu kepatuhan pasien (Basuki,2009).

Berdasarkan hasil studi pendahuluan pada bulan Desember 2017 didapatkan data bahwa dari 10 orang pasien yang menjalani kemoterapi $60 \%$ tidak menjalani kemoterapi sesuai siklus, $30 \%$ pasien mengatakan tidak kuat efek samping setelah melakukan kemoterapi, $40 \%$ pasien mengatakan tidak mendapatkan dukungan dari keluarga dalam melaksanakan kemoterapi dan $30 \%$ pasien mengatakan tidak menuntaskan sikluas kemoterapi karena tidak adanya dukungan dari perawat.

Rendam kaki air hangat adalah salah satu terapi hipertensi yang bermanfaat untuk mendilatasi pembuluh darah, melancarkan peredaran darah dan memicu saraf yang ada pada telapak kaki untuk bekerja (Tari Batjun, 2015). Hasil penelitian Batjun (2015) rendam kaki air hangat dalam waktu

\section{METODA PENELITIAN}

Jenis penelitian ini adalah Analitik. Desain penelitian adalah Cross Sectional Study yaitu melihat hubungan dukungan keluarga dan dukungan petugas kesehtan dengan kepatuhan pasien kanker dalam melaksanakan kemoterapi. Populasi dalam penelitian ini adalah semua pasien kemotrapi dengn teknik accidentl sampling.

\section{HASIL}

Tabel .1

Distribusi Frekuensi Kepatuhan Pasien

Kanker dalam Melaksanakan Kemoterapi di RS. Islam Siti Rahmah Padang Tahun 2018

\begin{tabular}{lcc}
\hline Kepatuhan & Frekuensi & Persentase \\
\hline Patuh & 14 & 46,7 \\
Tidak Patuh & 16 & 53,3 \\
\hline Jumlah & $\mathbf{3 0}$ & $\mathbf{1 0 0 , 0}$
\end{tabular}

Berdasarkan tabel 3.1 lebih dari lebih dari separoh $(53,3 \%)$ respondentidak patuh dalam melaksanakan kemoterapi.

Tabel 2

Distribusi Frekuensi Dukungan

Keluarga Pasien Kanker dalam Melaksanakan Kemoterapi di RS. Islam Siti Rahmah Padang Tahun 2018

\begin{tabular}{ccc}
\hline $\begin{array}{c}\text { Dukungn } \\
\text { Keluarga }\end{array}$ & Frekuensi & Persentase \\
\hline $\begin{array}{l}\text { Mendukung } \\
\text { Tidk } \\
\text { Mendukung }\end{array}$ & 11 & 36,7 \\
\hline Jumlah & $\mathbf{3 0}$ & $\mathbf{1 0 0 , 0}$ \\
\hline
\end{tabular}

Berdasarkan tabel 2 didaptkn lebih dari separoh $(63,3 \%)$ responden memiliki dukungan keluarga yang tidak mndukung

Tabel 3

Distribusi Frekuensi Dukungan Petugas
Kesehatan dalam Melaksanakan Kemoterapi di RS. Islam Siti Rahmah Padang, 2018

\begin{tabular}{ccc}
$\begin{array}{c}\text { Duk. } \\
\text { Petugas Kes }\end{array}$ & Frekuensi & Persentase \\
\hline $\begin{array}{c}\text { Dukung } \\
\text { Tidak } \\
\text { mendukung }\end{array}$ & Frekuensi & Persentase \\
\hline Jumlah & 14 & 46,7 \\
\hline
\end{tabular}


Berdasarkan tabel 3 lebih dari separoh $(53,3 \%)$ responden memiliki dukungan petugas yang tidak mendukung

\section{Hasil Analisa Bivariat}

Tabel 3.4

Hubungan Dukungan Keluarga dengan Kepatuhan Pasien Kanker Dalam Melaksanakan Kemoterapi di RS. Islam Siti Rahmah Padang
Pada tabel 4.4 di atas dapat dilihat bahwa responden yang patuh melaksanakan kemoterapi sebanyak $71,4 \%$ memiliki dukungan petugas kesehatan yang baik dibandingkan responden yang memiliki dukungan petugas kesehatan yang kurang sebanyak $25,0 \%$.

Hasil uji statistik Chi-Square didapatkan nilai $\mathrm{p}$ value $0,030 \quad(\mathrm{p}<0,05)$ artinya terdapat hubungan dukungan petugas

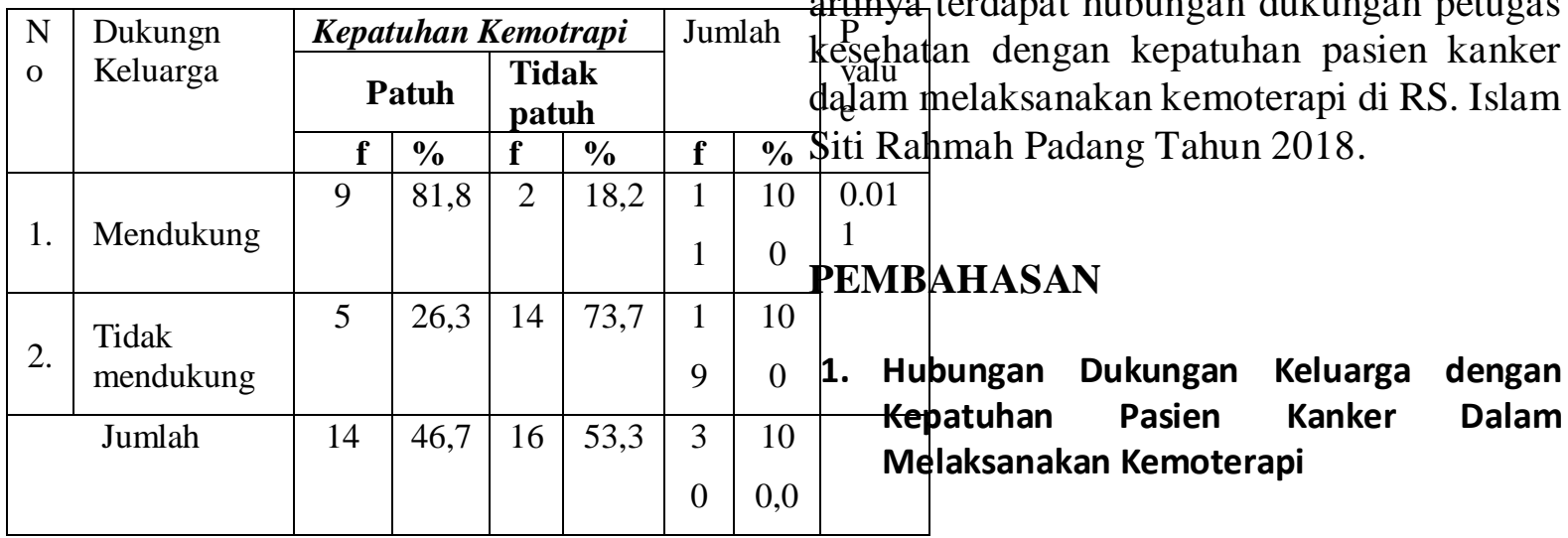
Berdasarkan hasil penelitian Pada tabel 4 diatas dapat dilihat bahwa responden yang patuh melaksanakan kemoterapi sebanyak $81,8 \%$ memiliki dukungan keluarga dibandingkan responden yang kelurga tidak mendukung sebanyak $26,3 \%$.

Hasil uji statistik Chi-Square didapatkan nilai $\mathrm{p}$ value $0,011 \quad(\mathrm{p}<0,05)$ artinya terdapat hubungan dukungan keluarga dengan kepatuhan pasien kanker dalam melaksanakan kemoterapi di RS. Islam Siti Rahmah Padang Tahun 2018. 16.

Tabel 5

Hubungan Dukungan Petugas dengan Kepatuhan Pasien Kanker Dalam Melaksanakan Kemoterapi di RS. Islam Siti Rahmah Padang Tahun 2018

\begin{tabular}{|c|c|c|c|c|c|c|c|}
\hline \multirow{3}{*}{$\begin{array}{l}\mathrm{N} \\
\mathrm{o}\end{array}$} & \multirow{3}{*}{$\begin{array}{l}\text { Dukungan } \\
\text { Tenaga } \\
\text { Kesehatan }\end{array}$} & \multicolumn{4}{|c|}{ Keptuhan Kemotrapi } & \multirow{2}{*}{\multicolumn{2}{|c|}{$\begin{array}{c}\text { Jumlah kePuarga dengan kepatuhan pelaksanaan } \\
\text { progaluam kemoterapi pada klien kanker. } \\
\text { e } \\
\text { Faktor-Faktor Pendukung Kepatuhan, }\end{array}$}} \\
\hline & & \multicolumn{2}{|c|}{$\begin{array}{l}\text { Menduku } \\
\text { ng }\end{array}$} & \multicolumn{2}{|c|}{$\begin{array}{r}\text { Tidak } \\
\text { Menduk } \\
\text { ung }\end{array}$} & & \\
\hline & & & $\%$ & $\mathbf{f}$ & $\%$ & $\mathbf{f}$ & \% Inenyebutkan bahwa faktor-faktor yang \\
\hline 1. & Dukung & 10 & 71,4 & 4 & 28,6 & 14 & 100,0 ing.g9pengaruh \\
\hline 2. & $\begin{array}{l}\text { Tidak } \\
\text { mendukun } \\
\mathrm{g}\end{array}$ & 4 & 25,0 & 12 & 75,0 & 16 & $\begin{array}{l}\text { 100,0 } \\
\text { pendidikan, kesakitan dan pengobatan, } \\
\text { keyakinan, sikap dan kepribadian, dukungan }\end{array}$ \\
\hline & Jumlah & 14 & 46,7 & 16 & 53,3 & 30 & tingkat ekonomi. \\
\hline
\end{tabular}

didapatkan bahwa responden yang patuh melaksanakan kemoterapi sebanyak 81,8\% memiliki dukungan keluarga yang baik dibandingkan responden yang kurang memiliki dukungan keluarga sebanyak 26,3\%. Hasil uji statistik Chi-Square didapatkan nilai $\mathrm{p}$ value $0,011 \quad(\mathrm{p}<0,05)$ artinya terdapat hubungan dukungan keluarga dengan kepatuhan pasien kanker dalam melaksanakan kemoterapi di RS. Islam Siti Rahmah Padang Tahun 2018.

Hasil penelitian ini sejalan dengan penelitian sebelumnya yang dilakukan oleh Siti Nurdjanah (2015) tentang hubungan dukungan keluarga dengan kepatuhan pelaksanaan program kemoterapi pada klien kanker di RSUP Dr. Sardjito Yogyakarta, menemukan bahwa hubungan dukungan kePuarga dengan kepatuhan pelaksanaan pryaglam kemoterapi pada klien kanker.

Faktor-Faktor Pendukung Kepatuhan, ang kat i 
disebutkan bahwa dukungan keluarga turut berperan dalam mendukung tingginya angka kepatuhan dan telah dibuktikan pula dalam hasil penelitian bahwa terdapat hubungan antara dukungan keluarga dengan kepatuhan yaitu bila dukungan keluarga tinggi maka angka kepatuhan juga tinggi atau pada dukungan keluarga rendah maka angka kepatuhannya juga rendah. Widyanto (2014) menyebutkan tentang dukungan yang diberikan oleh keluarga adalah supaya individu merasakan bahwa orang lain juga memperhatikan, menghargai serta mencintainya. Dukungan dapat berbentuk verbal atau non verbal. Dukungan verbal berupa penyampaian informasi, saran, nasehat serta penghargaan. Sedangkan dukungan non verbal berupa sikap mendengarkan, memperhatikan serta mengerti perasaan seseorang.

Analisis peneliti tentang adanya hubungan yang bermakna antara dukungan keluarga dengan kepatuhan pelaksanaan kemoterapi adalah kriteria usia responden yang terbanyak adalah rentang usia lebih dari 40 tahun. Pada rentang tersebut terdapat fase menjadi orang tua merupakan fase yang produktif dan kreatif. Di samping mendidik generasi muda maka tingkah laku yang kreatif dalam mengembangkan kultur atau kebudayaan merupakan salah satu wujud generativitas dan perilaku membangun. Mereka yang masuk dalam fase ini menurut Erikson akan mampu untuk memberi pengasuhan yang berarti. Menjadi orang tua yang berarti untuk orang lain, untuk bendabenda, untuk hasil karya dan ide-ide, merupakan persyaratan untuk menyelesaikan dengan baik proses psikososial fase yang berikutnya, yaitu fase integritas-ego atau integritas-diri dengan kutub yang berlawanan, yaitu putus asa. Orang yang mencapai integritas-diri adalah mereka yang dengan salah satu cara telah mengasuh generasi muda, yang tetap tegar menghadapi keberhasilan maupun kegagalan yang dialami sebagai orang tua, begitu juga mereka yang telah menghasilkan sesuatu, memperjuangkan ide atau keyakinannya. Karena memiliki tugas tersebut maka responden termotivasi untuk mengikuti dan mematuhi program kemoterapi yang sudah ditentukan oleh dokter agar responden dapat mewujudkan cita-citanya mengasuh generasi muda menuju kesuksesan.

Dengan dukungan keluarga sangat mempengaruhi pelaksanaan kemoterapi, sehingga keluarga dapat memberikan pelaksanaan kemoterapi, sehingga keluarga diharapkan dapat memberikan dukungan kepada pasien kemoterapi untuk melakukan kemoterapi dengan teratur dan sesuai jadwal. Dukungan yang dimaksudkan yaitu dengan cara mengantarkan pasien untuk kemoterapi dan menunggu mereka selama menjalani kemoterapi. Pelaksanaan kemoterapi kurang lebih dilakukan selama tujuh jam di rumah sakit. Pasien akan merasa tenang dan tidak jenuh karena ditunggui oleh keluarga. Dukungan keluarga yang tinggi akan membantu pasien untuk bangkit dan semangat dalam melakukan pengobatan sehingga kemungkinan untuk sembuh juga tinggi.

\section{Hubungan Dukungan Petugas Kesehatan dengan Kepatuhan Pasien Kanker Dalam Melaksanakan Kemoterapi}

Berdasarkan hasil penelitian didapatkanbahwa responden yang patuh melaksanakan kemoterapi sebanyak 71,4\% memiliki dukungan petugas kesehatan yang baik dibandingkan responden yang memiliki dukungan petugas kesehatan yang kurang sebanyak 25,0\%. Hasil uji statistik ChiSquare didapatkan nilai $\mathrm{p}$ value $0,030(\mathrm{p}<0,05)$ artinya terdapat hubungan dukungan petugas kesehatan dengan kepatuhan pasien kanker dalam melaksanakan kemoterapi di RS. Islam Siti Rahmah Padang Tahun 2018.

Hasil penelitian ini sebanding dengan penelitian sebelumnya yang dilakukan oleh Harina (2017) menemukan bahwa hubungan dukungan petugas kesehatan dengan kepatuhan pasien kanker dalam melaksanakan kemoterapi.

Kepatuhan pasien untuk menjalankan pengobatan yang ditawarkan oleh petugas kesehatan akan sangat dipengaruhi oleh cara petugas kesehatan dalam memberikan informasi tentang pengobatan tersebut. Agar 
seseorang mau melakukan suatu tindakan tertentu diperlukan dukungan yang efektif antara seorang provider dengan pasien dan/atau keluarganya. Dukungan yang tidak efektif antara petugas kesehatan dengan pasien dan atau keluarganya dapat mengganggu kepatuhan pasien (Basuki, 2009).

Sebagai seorang komunikator, tenaga kesehatan seharusnya memberikan informasi secara jelas kepada pasien. Pemberian informasi sangat diperlukan karena komunikasi bermanfaat untuk memperbaiki kurangnya pengetahuan dan sikap masyarakat yang salah terhadap kesehatan dan penyakit. Komunikasi dikatakan efektif jika dari tenaga kesehatan mampu memberikan informasi secara jelas kepada pasien, sehingga dalam penanganan suatu penyakit diharapkan tenaga kesehatan bersikap ramah dan sopan pada setiap kunjungan pasien (Notoatmodjo, 2014). Tenaga kesehatan juga harus mengevaluasi pemahaman pasien tentang informasi yang diberikan, dan juga memberikan pesan kepada pasien apabila terjadi efek samping yang tidak bisa ditanggulangi sendiri segera datang kembali dan komunikasi ke tenaga kesehatan.

Menurut asumsi peneliti bahwa adanya hubungan yang bermakna antara dukungan petugas kesehatan dengan kepatuhan pasien kanker dalam melaksanakan kemoterapi, hal ini terlihat dari hasil penelitian didapatkan bahwa adanya kecenderungan pasien yang tidak patuh melaksanakan kemoterapi pada dukungan petugas kesehatan yang kurang baik dan sebaliknya adanya kecenderungan semakin baik dukungan yang diberikan petugas kesehatan maka diikuti pula dengan semakin patuhnya pasien melaksanakan kemoterapi.

Adanya efek samping kemoterapi merupakan salah satu penyebab terjadinya kegagalan dalam melaksanakan kemoterapi tersebut. Hal ini bisa berkurang dengan adanya dukungan dari petugas kesehatan dalam hal ini memberikan informasi terhadap pasien sebelumnya, sehingga pasien akan mengetahui lebih dahulu tentang efek samping kemoterapi dan tidak cemas apabila setelah kemoterapi terjadi efek samping. Beberapa penelitian mengkonfirmasikan bahwa adanya semakin berat gejala efek samping obat maka akan semakin tidak patuh penderita dalam pengobatannya.

\section{KESIMPULAN}

Diharapkan bagi petugas kesehatan atau perawat yang memberikan asuhan keperawatan pada pasien kanker yang menjalani kemoterapi agar dapat memberikan dukungan maksimal dengan cara memberikan penjelasan yang lengkap tentang manfaat, efek samping dan cara kerja kemoterapi baik pada pasien maupun pada keluarga sehingga keluarga juga dapat memberikan dukungan yang maksimal pada pasien kanker yang menjalani kemoterapi tersebut.

\section{DAFTAR PUSTAKA}

Alle, Hardjanta, \& Suharsono, 2013. Faktor yang mempengaruhi kepatuhan pasien penyakit kanker menjalani kemoterapi di RS Kanker Dharmais Jakarta. Fakultas Psikologi Universitas Soegijapranata Semarang.

Friedman, 2010. Buku ajar keperawatan keluarga : Riset, Teori dan. Praktek. Jakarta : EGC.

Hidayat, 2014. Metode penelitian keperawatan dan teknis analisis data. Jakarta : Salemba Medika.

Harina, 2017. Faktor - faktor yang berhubungan dengan kepatuhan pasien kanker payudara dalam menjalani kemoterapi di Rumah Sakit Ropanasuri tahun 2017. Jurnal Vol II No. 22

Kemenkes RI, 2014. Hilangkan Mitos tentang Kanker. Jakarata: Pusat Komunikasi Publik Sekretariat Jenderal Kementerian

Kemenkes RI, 2016. Prevalensi penyakit kanker di Indonesia. Jakarata: Pusat Komunikasi Publik Sekretariat Jenderal Kementerian

Kova \& Miha, 2011.Impact of relaxation training according to yoga in daily life system on self esteem after breast cancer 
surgery. The jurnal of alternative and complementary medicine. Diakses dari: www.search.ebscohost.com Desember 2017.

Lubis \& Hasnida,2012.Dukungan sosial pada pasien kanker, Perlukah?. Medan: USU Press

Notoatmodjo, 2010. Metode Penelitian Kesehatan. Jakarta : Rineka Cipta.

Otto, 2015.Buku saku keperawatan onkologi. Alih bahasa oleh Jane Freyana Budi. Jakarta: EGC.

Price et al., 2012. Patofisiologi: Konsep Klinis. Proses-Proses Penyakit. Jakarta: EGC

Rasjidi,2013.Kemoterapi Kanker Ginekologi dalam praktik sehari-hari, Sagungseto.Jakarta

Sugiyono, 2014.Metode Penelitian Kuantitatif, Kualitatif, dan Kombinasi (Mixed. Methods). Bandung : Alfabeta

Smeltzer \& Bare, 2012. Buku Ajar Keperawatan Medikal. Bedah Brunner dan Suddarth (Ed.8, Vol. 1,2), Alih bahasa oleh Agung. Waluyo...(dkk), EGC, Jakarta.

Sukardja, 2013. Onkologi klinik. Edisi II. Surabaya: Airlangga University Press

Sirait, 2014. Survival analisys pada kanker serviks di RS Dr. Cipto Mangunkusumo Jakarta. Jurnal Epidemiologi Nasional. Volume 3

Susanti \&Tarigan,2012. Karakteristik mual dan muntah serta upaya penanggulangan oleh penderita kanker yang menjalani kemoterapi. Jurnal Vol II No. 32.

Sunaryo, 2014. Psikologi untuk keperawatan. Jakarta : EGC

Sudoyo, 2012. Buku Ajar Ilmu. Penyakit Dalam Jilid II edisi V. Jakarta: Interna Publishing.

WHO, 2014. The World Health Organization's Fight Against Cancer: Strategies That Prevent, Cure and Care. Available from:

http://www.who.int/cancer/modules

[accesed: Januari 2018] 